\title{
Roles of Molybdenum and Tungsten on Reheat Cracking Susceptibility of 2.25Cr Heat Resistant Steels
}

\author{
Hyun Je SUNG, Nam Hoe HEO* and Sung-Joon KIM \\ Graduate Institute of Ferrous Technology, POSTECH, Pohang, 37673 Republic of Korea. \\ (Received on June 20, 2016; accepted on September 2, 2016; J-STAGE Advance published date: \\ November 12, 2016)
}

\begin{abstract}
The rupture time of the tungsten-alloyed steel is much shorter than that of the molybdenum-alloyed steel. The fracture mode of the former steel is typically intergranular, but the latter steel shows a mixed fracture mode of intergranular and ductile. The shorter rupture time of the tungsten-alloyed steel is due to the active carbide formation reaction of tungsten in ferrite which depletes carbon within the matrix; the resulting higher segregation concentration of phosphorus at $\mathrm{GCls}$ and carbide-free PAGBs. The longer rupture time of the other steel arises from two factors: the molybdenum segregated at the interfaces as a grain boundary strengthener; the repulsive segregation between carbon and phosphorus which repels phosphorus from the interfaces and produces the lower segregation concentration of phosphorus.
\end{abstract}

KEY WORDS: phosphorus segregation; intergranular cracking; boiler; auger electron spectroscopy; carbides.

\section{Introduction}

The creep strength of heat resistant steels which are used for boilers of fossil power plants has been improved through the precipitation hardening by MX carbo-nitrides. ${ }^{1)}$ This concept has been applied to the development of the $\mathrm{T} / \mathrm{P} 24$ (2.25Cr1MoVNbTi) from the T/P22 (2.25Cr1Mo) heat resistant steel. $\left.{ }^{2}\right)$ The T/P23 $(2.25 \mathrm{Cr} 1.5 \mathrm{WVNbTi})$ heat resistant steel has been also developed through the replacement of molybdenum by tungsten. When these materials are applied to components of a large scale power plant, fusion welding is essential. Such a welding forms a coarse-grained heat affected zone (CGHAZ) adjacent to the fusion line due to the high temperature.

Generally, the T/P23 heat resistant steel shows a high intergranular cracking susceptibility in the CGHAZ, called the type III cracking or reheat cracking., ${ }^{3,4)}$ Such an intergranular cracking occurs mainly after post-weld heat treatment (PWHT) or during operation at elevated temperatures. ${ }^{3)}$ Lots of studies have reported that the segregation of impurities (especially, phosphorus) to the prior austenite grain boundaries (PAGBs) of the heat resistant steels causes the intergranular cracking by lowering the cohesive grain boundary strength. ${ }^{5-15)}$ It has reported that the T/P24 steel is much less susceptible to the intergranular cracking than the T/P23 steel, ${ }^{4)}$ although the reason is not clear.

It is the purpose of this study to investigate the intrinsic reason why the intergranular cracking susceptibility is higher in the tungsten-alloyed than the molybdenum-alloyed $2.25 \mathrm{Cr}$ steel.

\section{Experimental Procedures}

T/P23 and T/P24 steels of the same bulk phosphorus content were prepared by vacuum induction melting. The ingots were homogenized at $1200^{\circ} \mathrm{C}$ for 1 hour and hot-rolled to $12 \mathrm{~mm}$ thick plates. Chemical compositions of the steels are listed in Table 1. Rectangular bars with a dimension of $12 \times 12 \times 60 \mathrm{~mm}^{3}$ were machined from the plates in the hot-rolling direction. These bars were given to a heat treatment at $1050^{\circ} \mathrm{C}$ for 1 hour which is followed by air cooling and subsequently tempered at $750^{\circ} \mathrm{C}$ for 0.5 hour under an argon atmosphere. After these heat treatments, notched and cylindrical creep-rupture specimens for increasing the sensitivity to the intergranular cracking, which have a gauge length of $15 \mathrm{~mm}$, a gauge diameter of $6 \mathrm{~mm}$ and a notch

Table 1. Chemical compositions of the prepared steels (wt.\%).

\begin{tabular}{cccccccccccccccccccccccc}
\hline Steels & $\mathrm{C}$ & $\mathrm{Si}$ & $\mathrm{Mn}$ & $\mathrm{P}$ & $\mathrm{S}$ & $\mathrm{Cr}$ & $\mathrm{V}$ & $\mathrm{Al}$ & $\mathrm{Mo}$ & $\mathrm{W}$ & $\mathrm{Nb}$ & $\mathrm{N}$ & $\mathrm{B}$ & $\mathrm{Ti}$ & $\mathrm{Fe}$ \\
\hline $\mathrm{W}$ & 0.100 & 0.318 & 0.509 & 0.021 & $<0.002$ & 2.24 & 0.255 & 0.019 & - & 1.55 & 0.049 & 0.010 & 0.0013 & 0.016 & Balance \\
$\mathrm{M}$ & 0.096 & 0.297 & 0.478 & 0.021 & $<0.002$ & 2.26 & 0.248 & 0.014 & 0.95 & - & 0.048 & 0.013 & 0.0009 & 0.029 & Balance \\
\hline
\end{tabular}

\footnotetext{
* Corresponding author: E-mail: nhheo@postech.ac.kr

DOI: http://dx.doi.org/10.2355/isijinternational.ISIJINT-2016-373
} 
with $0.2 \mathrm{~mm}$ radius, $1.5 \mathrm{~mm}$ depth and an angle of $60^{\circ}$ at the center of gauge, were machined from the rectangular bars.

Welding simulation was conducted using a thermomechanical simulator (FDC, THERMECMASTOR-Z). Each specimen was induction-heated to $1300^{\circ} \mathrm{C}$ at a heating rate of $25^{\circ} \mathrm{C} / \mathrm{s}$ which is the limit heating rate for the precise temperature control. After holding at the temperature for 5 seconds, the specimen was fast cooled to room temperature by helium gas. Then, the creep-rupture test specimens to which a K-type thermocouple was attached were heated to $600^{\circ} \mathrm{C}$ at a heating rate of $1200^{\circ} \mathrm{C} / \mathrm{h}$. The creep-rupture test was carried out without soaking at the test temperature in the applied stress range of 100 to $200 \mathrm{MPa}$ using conventional creep-rupture testers.

In order to examine high temperature properties of welding-simulated specimens, tensile test was also performed by a thermo-mechanical simulator (FDC, THERMECMASTOR-Z). Tensile specimens had a gauge length of $8 \mathrm{~mm}$ and a gauge diameter of $7 \mathrm{~mm}$. After exposure to welding simulation explained above, the specimens were again induction-heated to $600^{\circ} \mathrm{C}$ which was creeprupture test temperature in this study at a heating rate of $10^{\circ} \mathrm{C} / \mathrm{s}$. As soon as the temperature reached $600^{\circ} \mathrm{C}$, the tensile test was started at a cross-head speed of $0.5 \mathrm{~mm} /$ min. During heating and tensile tests, an argon atmosphere was maintained to minimize the oxidation of the specimens.

The microstructure of specimens was examined using a field-emission scanning electron microscope (FE-SEM, ZEISS ULTRA-55). Thin-foil specimens were used for the analysis of carbides using a field-emission transmission electron microscope (FE-TEM, JEOL JEM-2100F) equipped with an energy-dispersive spectroscope (EDS, OXFORD). After the creep rupture tests, fracture surfaces were investigated, using the FE-SEM after ultrasonic cleaning in acetone.

In order to investigate changes in microstructure and segregation concentration of solutes with creep-rupture time, interrupted tests were performed under the $100 \mathrm{MPa}$ during the creep-rupture test. The interfacial segregation behavior of solutes was investigated, using an Auger electron spectroscope (AES, PHI 700). The notched AES specimens were machined from the interrupt tested and ruptured specimens. They were chilled with liquid nitrogen for 1 hour in the AES and in-situ fractured in a vacuum of $9 \times 10^{-8} \mathrm{~Pa}$ or better.
Typical parameters were a primary electron beam energy of $5 \mathrm{keV}$ and an electron beam size of about $200 \mathrm{~nm}$. About twenty points for grain boundary/carbide interfaces (GCIs) and carbide-free prior austenite grain boundaries (carbidefree PAGBs) were chosen for the AES analysis, respectively. The AES peaks used were $\mathrm{Fe}_{703}, \mathrm{P}_{120}, \mathrm{C}_{271}, \mathrm{~W}_{179}$ and $\mathrm{Mo}_{165}, 190,225$. Peak to peak height ratios (PHR, I/I $\mathrm{I}_{\mathrm{Fe}}$ ) obtained from the differential AES spectra were averaged.

\section{Results and Discussion}

After the welding simulation, the $\mathrm{W}$ and $\mathrm{M}$ steels showed a lath martensitic structure in which the prior austenite grain size is about $110 \mu \mathrm{m}$. Precipitates, which had formed after tempering at $750^{\circ} \mathrm{C}$ for 0.5 hour, were rarely observed after the welding simulation. Room temperature hardness of the martensitic structure is around $380 \mathrm{Hv}$, irrespective of the $\mathrm{W}$ and $\mathrm{M}$ steels [15]. In order to investigate elevated temperature properties of welding-simulated specimens, tensile test was performed. Figure 1 shows tensile test results at $600^{\circ} \mathrm{C}$ for the welding-simulated $\mathrm{W}$ and $\mathrm{M}$ specimens. Both of steels show similar mechanical properties: yield strength of about $550 \mathrm{MPa}$ and ultimate tensile strength of about 700 $\mathrm{MPa}$. Figure 2 shows changes in time to failure and reduction in area of the $\mathrm{W}$ and $\mathrm{M}$ steels with applied stress. The time to failure of the $\mathrm{W}$ steel is much shorter than that of the $\mathrm{M}$ steel, which causes the much lower reduction in area

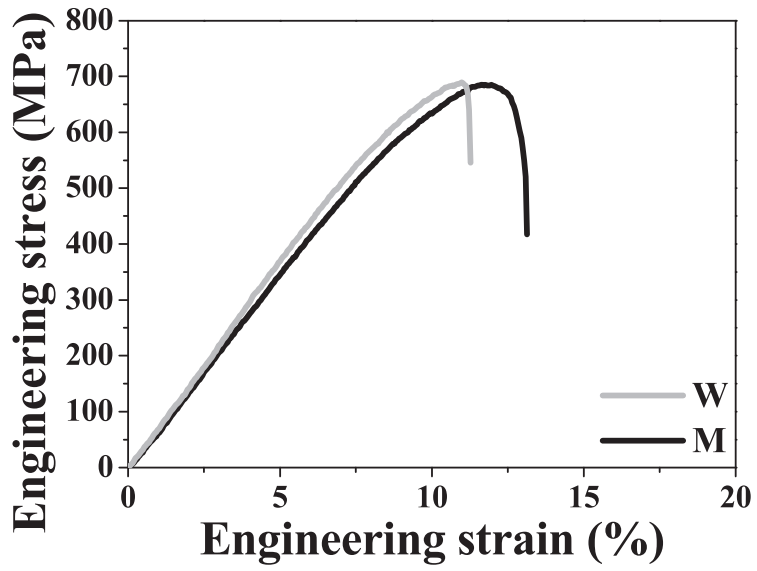

Fig. 1. Tensile test results for the welding-simulated $\mathrm{W}$ and $\mathrm{M}$ specimens at $600^{\circ} \mathrm{C}$.

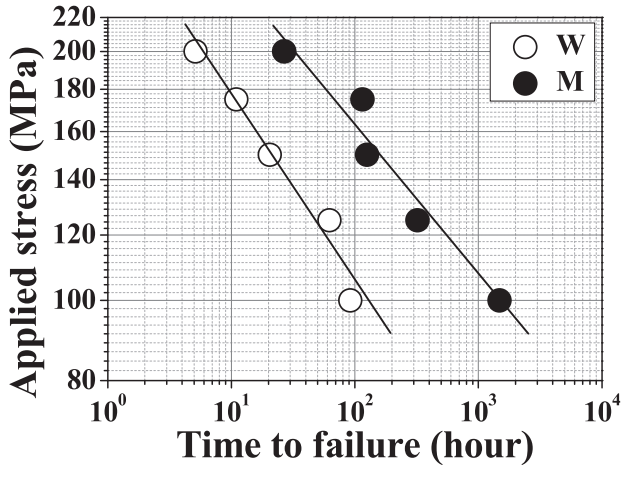

(a)

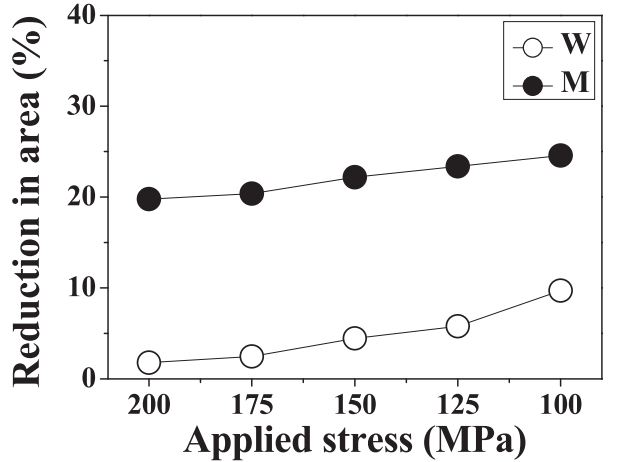

(b)

Fig. 2. (a) Changes in time to failure with applied stress at $600^{\circ} \mathrm{C}$ and (b) changes in reduction in area with applied stress. 
of the $\mathrm{W}$ steel. In both steels, the reduction in area increases gradually with increasing time to failure. This may be attributed to the softening by tempering during the rupture test. Fracture modes of the $\mathrm{W}$ and the $\mathrm{M}$ steels ruptured under $100 \mathrm{MPa}$ at $600^{\circ} \mathrm{C}$ are shown in Fig. 3. As expected from the reduction in area of Fig. 2(b), a typical intergranular fracture mode is observed in the $\mathrm{W}$ steel, while the M steel shows a mixed fracture mode of intergranular and ductile.

Figure 4 shows changes in size and distribution of precipitates with interrupted test and creep-rupture test time under $100 \mathrm{MPa}$ at $600^{\circ} \mathrm{C}$. The precipitation reaction has been more active in the $\mathrm{W}$ than the $\mathrm{M}$ steel. Fine precipitates are additionally observed within the matrix of the steels. The fraction and the size increase with interrupted creeprupture time. Equilibrium precipitates at $600^{\circ} \mathrm{C}$ of the $\mathrm{W}$ and $\mathrm{M}$ steels were additionally calculated using Thermo-Calc program including the TCFE7 database, as shown in Table 2. The $\mathrm{W}$ steel shows the main equilibrium precipitates of the tungsten-rich $\mathrm{M}_{6} \mathrm{C}$ and the chromium-, tungsten- and iron-rich $\mathrm{M}_{23} \mathrm{C}_{6}$. Meanwhile, those of the $\mathrm{M}$ steel are the chromium-, molybdenum- and iron-rich $\mathrm{M}_{23} \mathrm{C}_{6}$ and the molybdenum-rich $\mathrm{Mo}_{2} \mathrm{C}$.

Figure 5 shows scanning transmission electron micros-
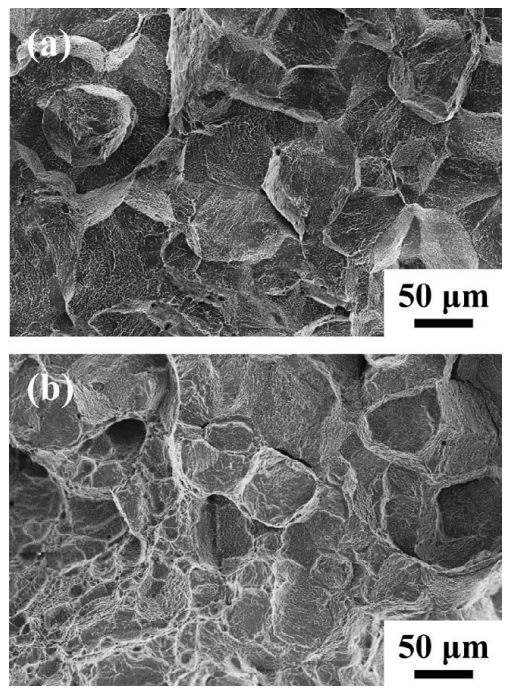

Fig. 3. The difference in fracture mode of the steels ruptured under $100 \mathrm{MPa}$ at $600^{\circ} \mathrm{C}$ : (a) $\mathrm{W}$ and (b) $\mathrm{M}$. copy-high angle annular dark field (STEM-HAADF) and EDS mapping images, which were obtained from the steels ruptured at $600^{\circ} \mathrm{C}$ under $100 \mathrm{MPa}$. The main carbides of the $\mathrm{W}$ steel are the chromium-rich $\mathrm{M}_{23} \mathrm{C}_{6}$ and the tungsten-rich $\mathrm{M}_{6} \mathrm{C}$ which are formed at the PAGBs. Meanwhile, those of the $\mathrm{M}$ steel are the chromium-rich $\mathrm{M}_{23} \mathrm{C}_{6}$ formed at the PAGBs and the molybdenum-rich $\mathrm{Mo}_{2} \mathrm{C}$ observed within the matrix. These results are consistent with the expectation of Table 2. In previous studies, ${ }^{17,18)}$ the initial needle-like $\mathrm{Mo}_{2} \mathrm{C}$ carbides formed in the T/P24 steel keep the coherency with the matrix during the creep-rupture test. As shown in Fig. 5(b), the $\mathrm{Mo}_{2} \mathrm{C}$ carbides become granular and coarsened with increasing creep-rupture time. ${ }^{19,20)}$ Vanadium- and niobium-rich MX carbo-nitrides, which are the fine precipitates of Fig. 4, were also observed along lath boundaries and
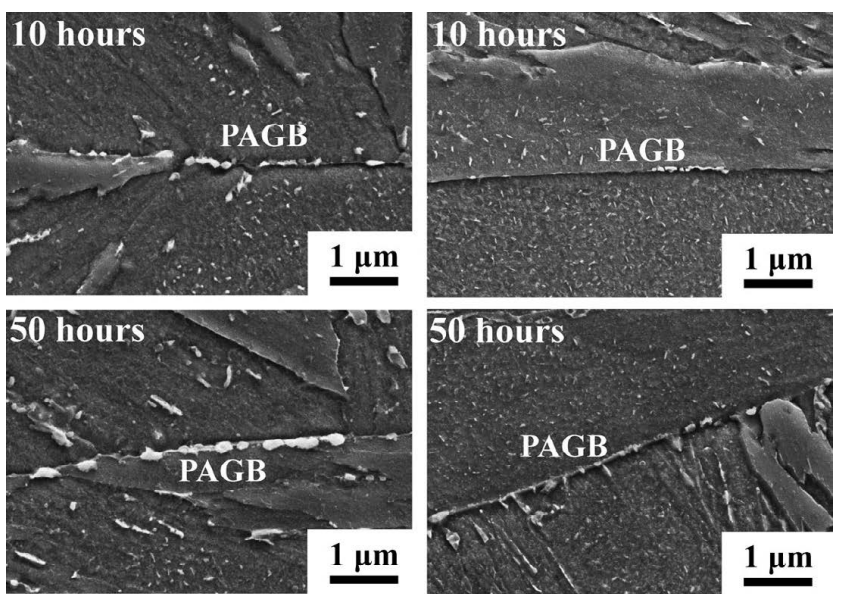

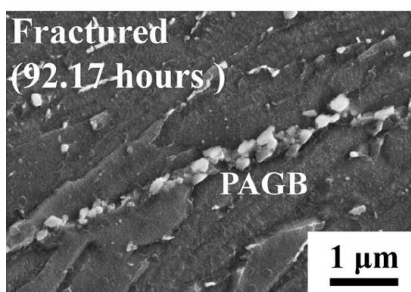

(a)



(b)
Fig. 4. Changes in size and distribution of precipitates with interrupted test and creep-rupture test time under $100 \mathrm{MPa}$ at $600^{\circ} \mathrm{C}$ : (a) W and (b) M. Here, PAGB means prior austenite grain boundary.

Table 2. Equilibrium precipitates at $600^{\circ} \mathrm{C}$ of the $\mathrm{W}$ and $\mathrm{M}$ steels which are calculated using Thermo-Calc software including the TCFE7 database.

\begin{tabular}{|c|c|c|c|c|c|c|c|c|c|c|c|c|}
\hline & & Volume fraction $\left(10^{-3}\right)$ & $\mathrm{C}$ & $\mathrm{N}$ & $\mathrm{Mn}$ & $\mathrm{Cr}$ & V & Mo & $\mathrm{W}$ & $\mathrm{Nb}$ & $\mathrm{Ti}$ & $\mathrm{Fe}$ \\
\hline \multirow{5}{*}{ W } & $\mathrm{M}_{6} \mathrm{C}$ & 8.513 & 0.018 & - & - & 0.007 & 0.013 & - & 0.704 & 0.002 & - & 0.256 \\
\hline & $\mathrm{M}_{23} \mathrm{C}_{6}$ & 6.438 & 0.047 & - & 0.027 & 0.419 & 0.017 & - & 0.222 & - & - & 0.268 \\
\hline & $\mathrm{V}(\mathrm{C}, \mathrm{N})$ & 3.337 & 0.135 & 0.027 & - & 0.037 & 0.670 & - & 0.054 & 0.030 & 0.002 & 0.043 \\
\hline & $\mathrm{Nb}(\mathrm{C}, \mathrm{N})$ & 0.548 & 0.121 & 0.002 & - & 0.062 & 0.025 & - & 0.007 & 0.738 & 0.043 & 0.002 \\
\hline & $\operatorname{Ti}(\mathrm{C}, \mathrm{N})$ & 0.254 & 0.051 & 0.169 & - & 0.001 & 0.007 & - & - & 0.001 & 0.771 & - \\
\hline \multirow{5}{*}{ M } & $\mathrm{M}_{23} \mathrm{C}_{6}$ & 10.075 & 0.051 & - & 0.002 & 0.480 & 0.006 & 0.194 & - & - & - & 0.267 \\
\hline & $\mathrm{Mo}_{2} \mathrm{C}$ & 2.708 & 0.071 & - & 0.003 & 0.041 & 0.192 & 0.683 & - & 0.007 & - & 0.002 \\
\hline & $\mathrm{V}(\mathrm{C}, \mathrm{N})$ & 1.713 & 0.119 & 0.052 & - & 0.014 & 0.736 & 0.014 & - & 0.040 & 0.003 & 0.022 \\
\hline & $\mathrm{Nb}(\mathrm{C}, \mathrm{N})$ & 0.521 & 0.117 & 0.002 & - & 0.029 & 0.021 & - & - & 0.789 & 0.041 & 0.001 \\
\hline & $\mathrm{Ti}(\mathrm{C}, \mathrm{N})$ & 0.491 & 0.047 & 0.173 & - & 0.001 & 0.007 & - & - & 0.001 & 0.771 & - \\
\hline
\end{tabular}



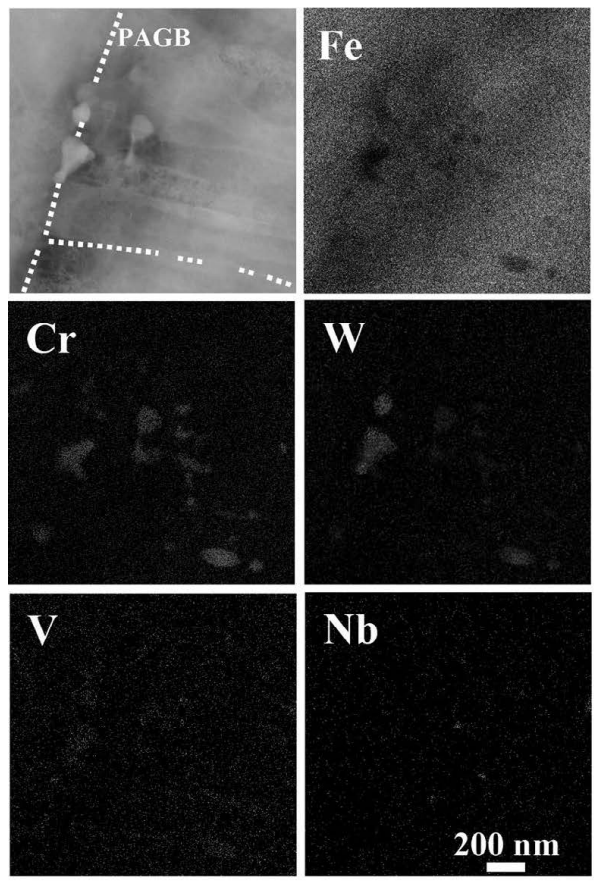

(a)
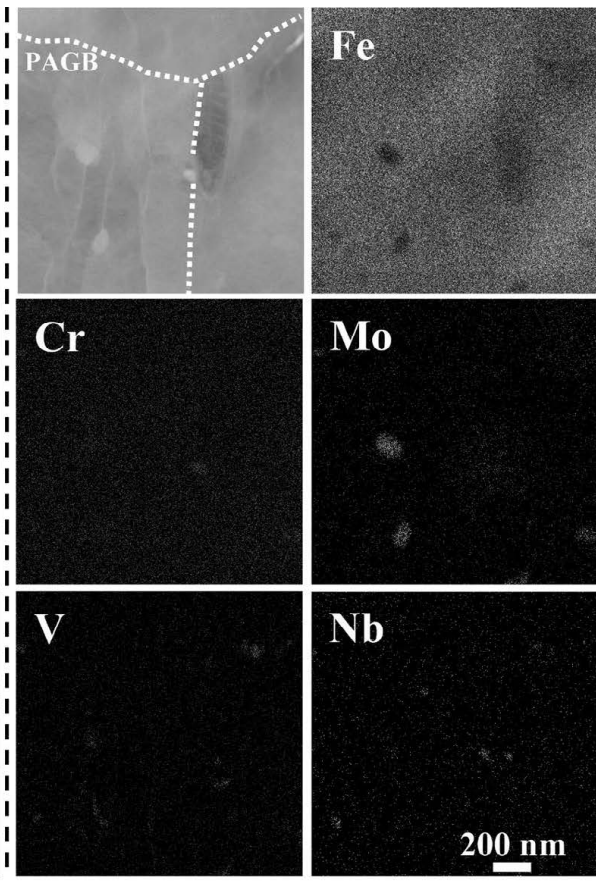

(b)

Fig. 5. Scanning transmission electron microscopy-high angle annular dark field (STEM-HAADF) and energydispersive spectroscopy (EDS) mapping images, which were obtained from the steels ruptured at $600^{\circ} \mathrm{C}$ under $100 \mathrm{MPa}$ (a) W and (b) M.

within the matrix of both steels.

Figure 6 shows surfaces in-situ fractured in the AES and representative Auger spectra obtained from the fracture surfaces of the AES specimens which were machined from the specimens rupture-tested under $100 \mathrm{MPa}$ at $600^{\circ} \mathrm{C}$. The segregation concentration of phosphorus is much higher at the GCI than the carbide-free PAGB, regardless of the steels. As reported in the previous research, ${ }^{7}$ the higher segregation concentration of phosphorus at the GCI is attributed to the higher interface energy of the GCI than the carbide-free PAGB. Although the bulk phosphorus content is same, the segregation concentration of phosphorus is overall much higher in the $\mathrm{W}$ than the $\mathrm{M}$ steel. The segregated tungsten is not observed in the $\mathrm{W}$ steel, while the carbon as well as the molybdenum are observed at the interfaces of the M steel.

Figure 7 shows changes in interfacial segregation kinetics of solutes with interrupted test and creep-rupture test time under $100 \mathrm{MPa}$ at $600^{\circ} \mathrm{C}$. As shown in Figs. 7(a1) and 7(a2) of the $\mathrm{W}$ steel, the segregation concentration of phosphorus increases abruptly with decreasing segregation concentration of carbon. The segregation concentrations of phosphorus and carbon show the maximum and the minimum under the final fracture situation, respectively. The segregation behaviors of the solutes in the $\mathrm{M}$ steel are similar those in the $\mathrm{W}$ steel. The segregation concentration of phosphorus of the M steel much lower than that of the $\mathrm{W}$ steel corresponds to the overall higher segregation concentration of carbon as well as the moderate concentration of molybdenum which is little changed during the rupture test.

Due to the very low solubility of tungsten in ferrite ${ }^{21)}$ which is compared to the high solubility of molybdenum and the higher driving force for the formation of carbides, ${ }^{22-24)}$ the larger amount of $\mathrm{M}_{23} \mathrm{C}_{6}$ and $\mathrm{M}_{6} \mathrm{C}$ carbides is formed at the expense of tungsten and carbon, as shown in Fig. 4(a).

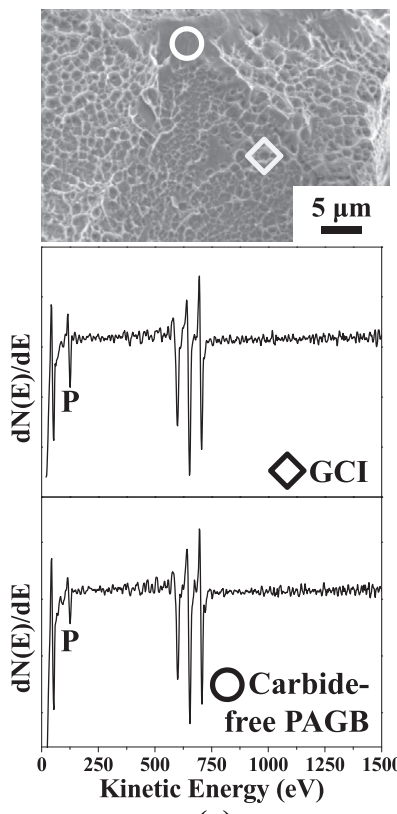

(a)

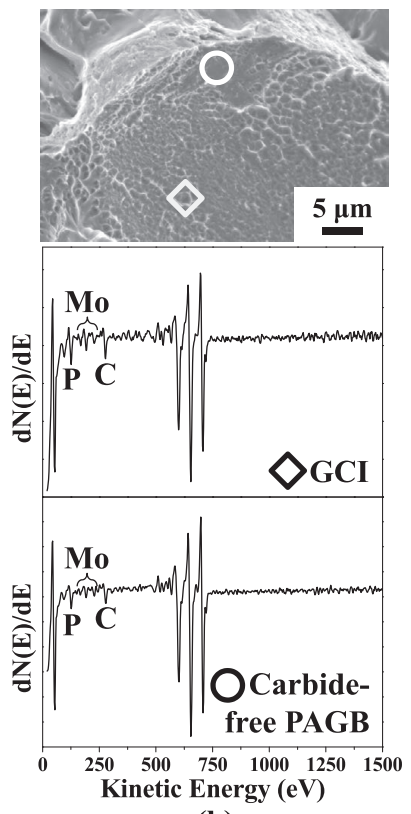

(b)
Fig. 6. Surfaces in-situ fractured in the AES and representative Auger spectra obtained from the fracture surfaces. The notched AES specimens were machined from the steels ruptured under $100 \mathrm{MPa}$ at $600^{\circ} \mathrm{C}$. Here, symbols $\diamond$ and $\bigcirc$ mean the GCI and the carbide-free PAGB, respectively: (a) W and (b) M.

As shown in Figs. 7(a1) and 7(a2), such an active carbide reaction causes the depletion of the dissolved tungsten and carbon. As a result, no tungsten and carbon segregated at the interfaces produces the abrupt increase in segregation concentration of phosphorus in the W steel. On the other hand, the segregation of the remaining carbon to the interfaces after some carbide reactions repels the phosphorus from the 

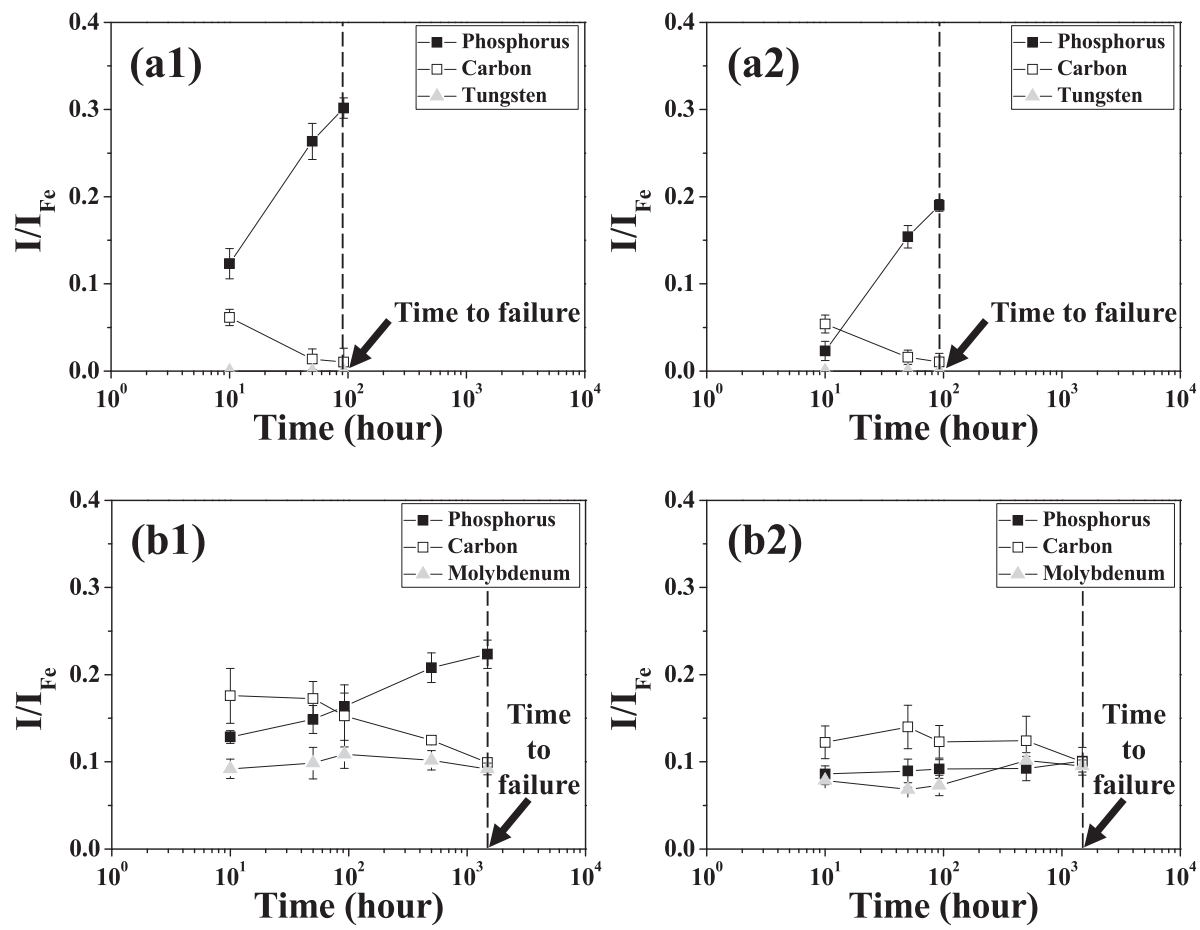

Fig. 7. Changes in interfacial segregation kinetics of solutes with interrupted test and creep-rupture test time: (a1) the GCI of the W steel, (a2) the carbide-free PAGB of the W steel, (b1) the GCI of the M steel and (b2) the carbidefree PAGB of the M steel.

interfaces through the repulsive segregation behavior. ${ }^{13,14)}$ Considering molybdenum and tungsten which are grain boundary strengtheners, ${ }^{25}$ ) the much longer time to failure of the M steel may be attributed to the lower phosphorus segregation concentration and the segregated molybdenum.

\section{Conclusions}

Reheat cracking susceptibility of $2.25 \mathrm{Cr}$ heat-resistant steels containing tungsten or molybdenum has been investigated, and the results are as follows.

(1) The time to failure of the tungsten-alloyed steel is much shorter than that of the molybdenum-alloyed steel. The fracture mode of the tungsten-alloyed steel is typically intergranular, but the molybdenum-alloyed steel shows a mixed fracture mode of intergranular and ductile.

(2) The tungsten-alloyed steel shows the larger amount of precipitates along PAGBs. Their size is bigger in the $\mathrm{W}$ than the $\mathrm{M}$ steel. The segregation concentration of phosphorus at GCIs and PAGBs is much higher in the tungsten- than the molybdenum-alloying steel.

(3) The much shorter time to failure of the tungstenalloyed steel is due to the concurrent reaction between three factors: the very low solubility of tungsten in ferrite arising from the higher affinity of tungsten and carbon for forming carbides; the absence of the repulsive segregation between carbon and phosphorus; the resulting higher segregation concentration of phosphorus at the GCIs and the carbide-free PAGBs. Meanwhile, the much longer time to failure of the molybdenum-alloyed steel can be attributed to two factors: the molybdenum segregated at the interfaces which acts as a grain boundary strengthener; the repulsive segregation between carbon and phosphorus which results in the much lower segregation concentration of phosphorus at the interfaces.

\section{Acknowledgments}

The authors thank Korea Institute of Energy Technology Evaluation and Planning (Project No: 20152010103430) for the financial support and Mrs. J. H. Yoon in Korea Institute of Science and Technology for the AES analysis.

\section{REFERENCES}

1) W. Bendic, J. Gabrel, B. Hahn and B. Vandenberghe: Int. J. Press. Vessel. Pip., 84 (2007), 13.

2) J. C. Vaillant, B. Vandenberghe, B. Hahn, H. Heuser and C. Jochum: Int. J. Press. Vessel. Pip., 85 (2008), 38.

3) F. Abe, T. U. Kern and R. Viswanathan: Creep Resistant Steels, Woodhead Publishing Ltd, Cambridge, (2008).

4) A. Dhooge and J. Vekeman: Weld. World, 49 (2005), 75

5) N. H. Heo and S.-J. Kim: Mater. Sci. Eng. A, 556 (2012), 533.

6) N. H. Heo, J. C. Chang and S.-J. Kim: Mater. Sci. Eng. A, 559 (2013), 665.

7) N. H. Heo, J. C. Chang, K. B. Yoo, J. K. Lee and J. Kim: Mater. Sci. Eng. A, 528 (2011), 2678.

8) C. A. Hippsley, J. F. Knott and B. C. Edwards: Acta. Metall., 29 (1980), 869.

9) C. A. Hippsley, J. F. Knott and B. C. Edwards: Acta. Metall., 30 (1982), 641.

10) R. Raj and M. F. Ashby: Acta. Metall., 23 (1975), 653.

11) J. Shin and C. J. McMahon, Jr.: Acta Metall., 32 (1984), 1535.

12) R. D. K. Misra: Acta Mater., 44 (1996), 885.

13) H. J. Grabke: Steel Res., 57 (1986), 178.

14) Y. Q. Weng and C. J. McMahon, Jr.: Mater Sci. Technol., 3 (1987), 207.

15) H. J. Sung, N. H. Heo and S.-J. Kim: Metall. Mater. Trans. A, 47 (2016), 1975.

16) K. Miyata and Y. Sawaragi: ISIJ Int., 41 (2001), 281.

17) A. Shibli: Coal Power Plant Materials and Life Assessment, Woodhead Publishing Ltd, Cambridge, (2014).

18) Y.-N. Shi and P.-M. Kelly: J. Mater. Sci., 37 (2002), 2077.

19) R. A. Varin and J. Haftek: Mater. Sci, Eng., 62 (1984), 129.

20) K. R. Williams and B. Wilshire: Mater. Sci. Eng., 28 (1977), 289.

21) T. B. Massalski: Binary Alloy Phase Diagrams, ASM International, Materials Park, OH, (1990).

22) S. K. Gupta and K. A. Gingerich: J. Chem. Phys., 74 (1981), 3584

$23)$ J. A. M. Simoes and J. L. Beauchamp: Chem. Rev., 90 (1990), 629.

24) Y.-R. Luo: Comprehensive Handbook of Chemical Bond Energies, CRC Press, Boca Raton, (2007).

25) M. P. Seah: Acta Metall., 28 (1980), 995. 